\title{
Research on Quantification and Design Evaluation of Visual Perception Beauty of Purple Clay Teapot
}

\author{
Dong Hao ${ }^{1}$, Han Rong ${ }^{2}$, Zhang Hong ${ }^{3}$ \\ ${ }^{1}$ A rt school, Jiang Su U niversity, ZhenJ iang,J iangSu,212013,China \\ ${ }^{2}$ A rt school, Jiang Su University, ZhenJ iang,J IangSu,212013,China \\ ${ }^{3}$ A rt school, Jiang Su University, ZhenJ iang,J iangSu,212013,China
}

\begin{abstract}
Yixing purple clay teapot is a famous product due to the evolution of tea culture, which has been continued to this day and gradually become a system of cultural hybridity. It is because of its profound cultural and historical accumulation that it has achieved its position in pottery. With the continuous improvement in technology and the accumulation of experience of generations of purple clay artisans, the patterns of the purple clay pots they make are also in a great variety of fantasies. This paper will explore the design aesthetic basis of purple clay teapot from two directions of the visual angle of purple clay teapot, namely the modelling of purple clay teapot and its decoration.
\end{abstract}

\section{Introduction}

As an art, the prominent feature of "utensil art" in artistic expression is its artistic molding of three-dimensional space, among which virtual space is an indispensable and important part in the utensil plastic art. At the same time, the design language of utensil art is also very abundant and multiple. The material property, materials, different craft and expression means of different utensils provide a wide space for the formation of different features of the artifacts. ${ }^{1}$

Although the purple clay culture only has a short time of five or six hundred years, its development must be inseparable from tea and economic cultures, and so to speak, the history of purple clay is the portrayal of social development. The artistic design philosophy that "art comes from life and is higher than life" has deeply influenced the purple sand artistic creation. Purple clay teapot itself is an

1 X u Xiu Tang. Chinese Purple Sand. Shanghai A ncient B ooks Publishing House. 1998 appliance closely linked to the life, so for its creation, we must learn from and imitate life. In addition to the fine raw materials and production techniques, a good purple sand artwork cannot leave the design of purple sand craftsman, that is, the modeling and decoration of the purple sand pot. Each pot is unique because of the emotion and effort of the craftsman. Below, we will get a glimpse of the design aesthetics of purple sand pot from the two aspects of modelling and decoration.

\section{Plastic art of purple sand pot}

The models of purple sand pot are rich, with numerous styles, complete specifications and thousands of shapes, which are probably peerless among various arts and crafts. Look closely at the shape of the whole purple sand pot, though it is divided into various categories, such as plain, decorative pattern, and muscle grain vessels, they all have a big commonality -- imitation, and the word "imitation" is often confused with "plagiarism", which is regarded as a derogatory term by people. But for an object, once it wants to be developed, it has to follow the creation rule of

Corresponding author's e-mail: dongha03113@163.com 
"imitation -- gradual advance -- innovation" 2. Therefore, most of the purple sand pot models are of imitative nature.

\subsection{Plain purple sand pots}

M ost of the plain purple sand pots are round, square and hexagonal in shape, which is the earliest model in the history of purple sand pots, without too much decoration, plain and el egant. The plain purple sand pots have succinct lines, harmonious and unified points, lines and planes, concise and graceful, which exude the artistic charm of primitive simplicity and elegance.

The proportions of the modeling for the plain purple sand pots are particular because there is no decoration on them. In the process of pot making, the purple clay artist should consider the relationship between the facade lines and the plane configuration, and how to balance the proportion of the whole pot to make it harmonious and unified.

The plain purple sand pots are less bionic, but there are some references, such as the classic " $X \mathrm{i}$ Shi pot" made by $X u$ You Quan in the Ming Dynasty. The "Xi Shi pot", also known as the "Xi Shi pot with the handle upside down", was originally called the "Xi Shi breast", which means the shape of the pot resembles the plump breasts of the beauty $\mathrm{X}$ i Shi. Indeed, the pot looks like a full breast, the pot knob like a nipple; The lid is designed with a truncated lid, which perfectly matches the body at the joint and keeps consistent with the whole body; ${ }^{3}$ The spout is slightly out of the body at an angle of 45 degrees, which is skillfully transferred by the technique of dark connection, so that the spout and the body are connected naturally, as if it were growing out of the body without any trace of external connection; The handle is an "inverted handle" design. The handle of the normal purple sand pot is thick at the top and thin at the bottom, and the other half is large at the top and contracted at the bottom. But the "Xi Shi pot" is exactly the opposite, and this design is in essence for the coordination of the whole pot shape. In the plain purple sand pot bionic models, there is much more than just the "Xi Shi pot". Classic

${ }^{2} \mathrm{Li}$ Li Xin. Imitation Theory of Reconstruction of Creation -- the Origin of the Shape of Purple Sand Ware. [J]. Creativity and Design. 2012.02

3 Zhou Guo Xin. A Brief A nalysis of the Artistic Charm of "Xi Shi Pot". [J]. Shandong Ceramics. 2019.6 models such as "Wen Dan", "Long Dan" and "Qin Q uan" are more or less imitated.

In the purple sand pots, the type that can see the skill of purple sand craftsman most is "plain" purple sand pot. With the same modelling, the same set of contour curve, the shape of different patterns can be shaped, which is the embodiment of the artisan level, so there is a effect that "a miss is as good as a mile.". 
Table 1: Plain Purple Sand Pot (painted by the author)

\begin{tabular}{|c|c|c|c|c|c|c|c|c|c|}
\hline $\begin{array}{c}\text { Spherical } \\
\text { Pot }\end{array}$ & $\begin{array}{c}\text { Hemisp } \\
\text { herical } \\
\text { Pot }\end{array}$ & $\begin{array}{l}\text { Oblate } \\
\text { Pot }\end{array}$ & $\begin{array}{l}\text { Cylind } \\
\text { rical } \\
\text { Round } \\
\text { Pot }\end{array}$ & $\begin{array}{c}\text { Trapezo } \\
\text { idal } \\
\text { Round } \\
\text { Pot }\end{array}$ & $\begin{array}{c}\text { Square } \\
\text { Pot }\end{array}$ & $\begin{array}{l}\text { Hexago } \\
\text { nal Pot }\end{array}$ & $\begin{array}{c}\text { M itral } \\
\text { Pot }\end{array}$ & $\begin{array}{c}\text { Eaves } \\
\text { Tiles } \\
\text { Pot }\end{array}$ & $\begin{array}{l}\text { Straw- } \\
\text { hat Pot }\end{array}$ \\
\hline & & & & & & & & & \\
\hline & & & & & & 5 & & & \\
\hline & & & & & & & & & \\
\hline & & & & & & & & & \\
\hline & & & & & & & & & \\
\hline 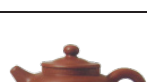 & & & & & & & & & \\
\hline & & & & & & & & & \\
\hline
\end{tabular}

\subsection{Flower purple clay teapot}

In the three categories of plain, flower and muscle vein utensils, the "flower" class shows a very strong imitation nature. In the production of flower type purple clay pot, craftsmen need to extract the aesthetic part of the natural form, and must conform to the pragmatic principle of reasonable function, beautiful vision and safe use when incorporating the design; Or directly shape the components of the purple sand pot into a natural shape. This technique is mostly applied to the spout, handle and knob of the pot.

A mong the traditional models of purple sand teapot $t$, the fish-dragon pot, pine-bamboo-plum pot, butterfly pot and lotus pot are all representative works of flower modelling. Most of these classic wares have the design of imitating nature. ${ }^{4}$ There are three stages of bionics of flower purple sand implement: the first is natural and lifelike. Any creature in the universe is the figurative language of flower purple sand implements. There is no incongruity in its vivid imitation. The second is the unity of ecology and morphology. In the production of flower purple clay pots, the variety of natural images is often skillfully applied to the key parts of the wares, so that the flower wares are not only variegated but also without losing their functionality. The third is rich in verve. The verve can only be understood, it is really difficult to describe with words, which is the artistic appeal of

4 Xu Xiu Tang. Chinese Purple Sand. Shanghai A ncient B ooks Publishing House. 1998 an object from the inside out, that is, the so-called artistic charm. If it is only the lifelike restoration of nature, that is only a low-level imitation, then how to promote the imitation to the level of art, rather than the reproduction of life? This is a subject that the purple sand craftsman has been studying all his life.

Table 2: Flower Purple Sand Pot (painted by the author)

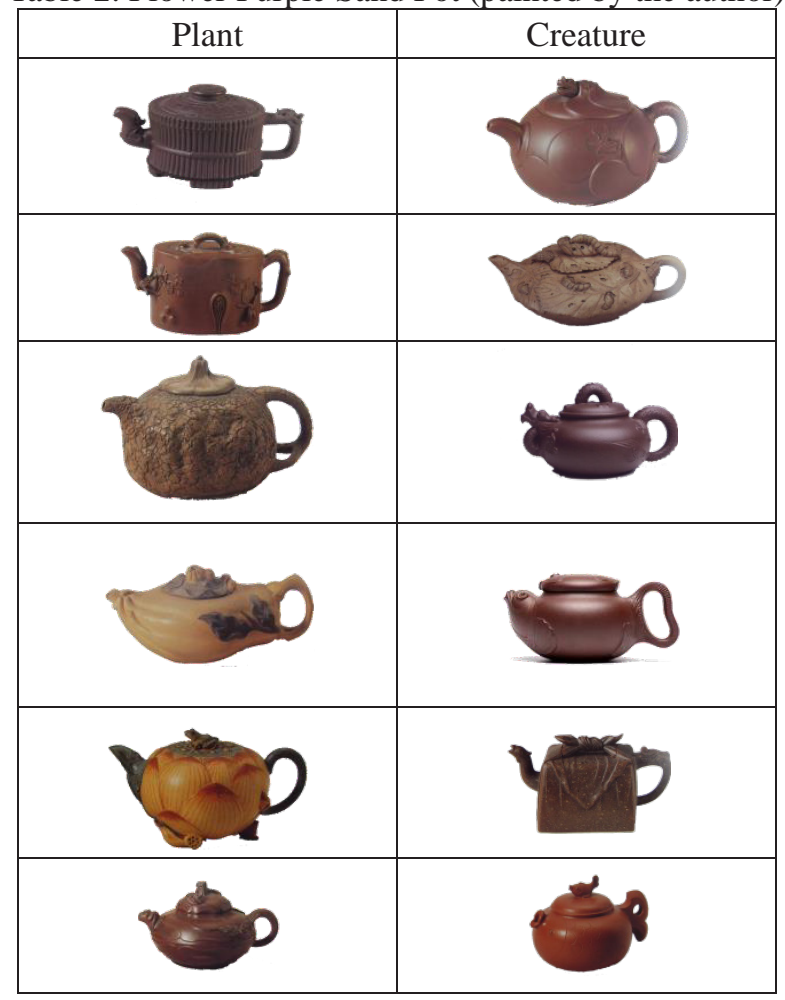




\subsection{Ribbed of purple clay teapot}

The distinctive design aesthetics of muscle vein utensils is formed by dividing the shapes of melon edges, petals and cloud and water veins in the nature into several parts and incorporating the vivid and interesting lines into the precise and strict design. In the natural world, flowers such diamond flower, daffodil, pumpkin, persimmon and so on are the imitation object of muscle vein utensils. The vein gradually transits from the spout to the body and then to the bottom of the pot, and the petal surface size is mostly uniform. The difference of pot type just depends on the number of petals, the incongruity of sag direction.
M uscle vein utensil is not only found in purple clay pots. There are many types of muscle vein utensils within the pottery category. However, due to the strong plasticity of purple sand clay, the muscle vein utensil has a sense of vitality in addition to imitating the natural texture of plants, a unique design aesthetics endowed with vitality.

The unique design of the purple clay teapot is the generations of purple clay artists Cawareness of life and love for nature. The ubiquitous creatures can be used for reference. The purple sand craftsman strictly abides by this principle of perfect combination of aesthetics and practicality, and innovates it, endowing it with a new design language.

Table 3: M uscle Vein Utensil Purple Sand Pot (painted by the author)

\begin{tabular}{|c|c|c|c|}
\hline Round Bar Shape & $\begin{array}{c}\text { Shape of a Diamond } \\
\text { Flower }\end{array}$ & $\begin{array}{c}\text { Shape of } \\
\text { a Sunflower@ Petals }\end{array}$ & Variation \\
\hline & & & \\
\hline
\end{tabular}

\section{The decorative arts aesthetics of the purple clay teapot}

The purple clay teapot is a combination of sculpture, painting, and calligraphy. The character of purple clay pottery is simple and tasteful, and heavy make-up has nothing to do with it. But even if it@ plain, it needs a little decoration. A t the same time, because the artisans focus on different pot art, pursue different aesthetics, purple clay pottery forms its own unique style, and changes on this basis.

\subsection{The self - decoration of purple clay pots}

The most important thing for the decoration of the purple sand pot is naturally the properties of the raw material. By making full use of the texture of purple clay and its characteristics, the purple sand pot is decorated, which is defined as purple sand self-decoration.

There are many kinds of purple clay, which can be divided into three categories: purple clay, original green clay and red clay. Not only do the three types of mud have different colors, they also have different chemicals in them. Different materials can bear different firing temperature, so the grasp of the character of the clay is the standard 
to test whether a purple sand artisan has been personality of the clay can it be "played on the introduced to the industry. Only by mastering the hand"

Table 4: Chemical Composition of Purple Clay ${ }^{5}$

\begin{tabular}{|c|c|c|c|c|c|c|c|c|c|c|c|}
\hline \multirow{2}{*}{$\begin{array}{l}\text { Serial } \\
\text { Number }\end{array}$} & \multirow{2}{*}{$\begin{array}{c}\text { Name of } \\
\text { Raw } \\
\text { M aterial }\end{array}$} & \multicolumn{10}{|c|}{ Chemical Composition (\%) } \\
\hline & & $\mathrm{Na}_{2} \mathrm{O}$ & $\mathrm{MgO}$ & $\mathrm{Al}_{2} \mathrm{O}_{3}$ & $\mathrm{SiO}_{2}$ & $\mathrm{~K}_{2} \mathrm{O}$ & $\mathrm{CaO}$ & $\mathrm{TiO}_{3}$ & $\mathrm{Fe}_{2} \mathrm{O}_{3}$ & $\begin{array}{l}\mathrm{SiO}_{2} / \\
\mathrm{AlO}_{3}\end{array}$ & $\begin{array}{l}\mathrm{R}_{x} \mathrm{O}_{\mathrm{y}} / \\
\mathrm{Al}_{2} \mathrm{O}_{3}\end{array}$ \\
\hline 1 & $\begin{array}{c}\text { Bai Ma } \\
\mathrm{Zi}\end{array}$ & 0.37 & 0.72 & 28.40 & 63.07 & 1.35 & 0.47 & 0.84 & 3.77 & 2.22 & 3.10 \\
\hline 2 & $\begin{array}{c}\text { Ben Shan } \\
\text { Clay A }\end{array}$ & 0.03 & 0.57 & 26.30 & 62.64 & 1.23 & 0.36 & 0.68 & 7.18 & 2.38 & 4.19 \\
\hline 3 & $\begin{array}{c}\text { Di Cao } \\
\text { Qing }\end{array}$ & 0.25 & 0.90 & 25.66 & 59.95 & 3.45 & 0.34 & 0.65 & 7.79 & 2.34 & 2.59 \\
\hline 4 & $\begin{array}{l}\text { Hei Dun } \\
\text { Tou }\end{array}$ & 0.13 & 0.63 & 29.82 & 56.33 & 1.17 & 0.60 & 0.71 & 9.62 & 1.89 & 2.99 \\
\hline 5 & Hei Liao & 0.23 & 0.61 & 22.19 & 61.53 & 2.54 & 0.41 & 1.00 & 10.48 & 2.77 & 4.52 \\
\hline 6 & $\begin{array}{l}\text { Hong } \mathrm{Ma} \\
\mathrm{Zi}\end{array}$ & 0.28 & 0.68 & 22.53 & 65.25 & 1.47 & 0.43 & 0.88 & 7.48 & 2.90 & 4.26 \\
\hline 7 & Red Clay & 0.03 & 1.01 & 25.69 & 63.13 & 2.81 & 0.44 & 0.75 & 5.13 & 2.46 & 2.42 \\
\hline 8 & $\begin{array}{l}\text { Qing } \\
\text { Long } \\
\text { M ountain } \\
\text { Slope } \\
\text { Clay }\end{array}$ & 0.20 & 1.22 & 31.05 & 55.23 & 3.81 & 0.43 & 0.76 & 6.29 & 1.78 & 1.46 \\
\hline 9 & $\begin{array}{c}\text { Ordinary } \\
\text { Purple } \\
\text { Clay }\end{array}$ & 0.03 & 0.77 & 23.12 & 63.89 & 3.00 & 0.29 & 0.65 & 7.24 & 2.76 & 3.58 \\
\hline 10 & $\begin{array}{l}\text { Sesame } \\
\text { Section }\end{array}$ & 0.29 & 1.09 & 32.24 & 58.83 & 2.87 & 0.46 & 0.81 & 2.41 & 1.82 & 1.68 \\
\hline 11 & Zhu Ni & 0.03 & 1.24 & 24.38 & 61.10 & 3.14 & 0.44 & 0.56 & 8.12 & 2.51 & 2.03 \\
\hline 12 & $\begin{array}{c}\text { Original } \\
\text { Green } \\
\text { Clay }\end{array}$ & 0.23 & 0.71 & 24.02 & 61.55 & 2.73 & 0.35 & 0.75 & 3.45 & 2.65 & 3.62 \\
\hline
\end{tabular}

\footnotetext{
${ }^{5}$ Wu Juan, Zhang Mao Lin, Wu Jun Ming, Li Qi Jiang, Yu Yong Bin, Liang Duo and Fang Tao. Study on
} Properties of Yixing Purple Clay. [] ]. 2011. 
In the pure decoration technique of the purple clay pot, I divided the clay painting, paste-on-paste decoration, printing board decoration, twisted clay into self-decoration of purple clay, which is the exchange between the clay self.

The techniques of clay painting and paste-on-paste decoration were popular in the early Qing Dynasty in the late 17th century. Their craft is to paint in piles flowers and birds or landscape patterns with other colored mud or natural mud on top of finished mud with a certain amount of humidity. The patterns heaped up are like thin reliefs, which requires a great deal of $K$ ung fu from the purple sand artisans, who needs to have calligraphy, painting, plastic paste and other skills at the same time, and which has very high requirements for his aesthetic accomplishment.

The principle of printing for me decoration is the same as that of sculpture, which is to use a mold to imprint the required pattern, and then cover the clay plate on the template, gently press. The stencil is mostly inlaid, and the effect on the clay sheet is a raised pattern. Because the printed patterns on the printed board cannot be processed externally, most of them are square objects.

The twisted clay decoration is an inevitable product, and its craft was discovered accidentally by the potter in the process of pottery making. The pattern of two kinds of clay colors superimposed on each other has appeared as early as in ancient pottery, and its adornment craft is the product of accident to necessity. The twisted clay pots vary in appearance. In its design, the emphasis on nature makes the surface of the pot show a kind of natural and abstract, giving a strong visual impact, but in the sense of touch, the body is smooth and the texture is consistent. The advanced twisted clay artisan can control the style of the whole twisted clay pot, creating an abstract pattern under the control of his aesthetic.

\subsection{The exterior decoration of the purple clay pot}

In the decoration of the purple clay pot, besides self-decoration, there are inlaying techniques, silver/tin wrapping, color adding and other decoration techniques combined with other materials.

Inlay technique is widely used in many implements, which was originally a means for the families of some wealthy officials to show their status and wealth. In history, there were some purple clay pots inlaid with jade and glaze beads. However, with the progress of the times, the improvement of peoples aesthetic level, and the improvement of the thought and aesthetics of the clay pot artisans, people gradually found that inlay decoration with appropriate design can certainly lift the beauty of purple clay pot, but too complex decoration did not improve the overall beauty of purple clay pot, but made it become vulgar, which is far from the original intention of making purple clay pot. In the 1970s, the Y ixing Purple Clay Craft Factory developed the filigree mosaic technique, which is said to have existed in ancient times, but this vessel has not been handed down.

The method of tin packing in purple sand existed in ancient times, which was popular in the reign of Dao Guang in the Qing Dynasty. It@ a modeling division under the tin pot category, which belongs to the style of tin diet utensils of the style of literati at that time. The production of tin pots with literati style is mainly made of clay mud as base, and in order to meet the fine requirements of tin-ware, the people who make clay base are often famous artisans with higher cultural attainment. The artisans with higher cultural accomplishment have more ability to impart knowledge and accumulate experience than the craftsmen with lower level in the society.

The art of purple sand and color decoration began in the Kangxi Period of the early Qing Dynasty, when porcelain production reached its peak and the craft and color decoration were mature. During the Yong Zheng and Q ianlong Periods of the Qing Dynasty, the production of purple sand utensils has been relatively mature, with the superb technique, but its innovation is not enough, together with the color adding process was prevailing in the ceramic industry, it is no doubt that purple sand color adding began to appear. The color adding process is a great test of the craftsman $\odot$ design idea and aesthetic accomplishment. The appreciation of color adding purple sand is strong, it gathers Chinese painting, calligraphy, design in one, integrates purple sand modeling, glaze color in a body, not only steady, primitive, typical, but also sumptuous, elegant, luxurious, with high artistic appreciation value."6

Purple clay decoration aesthetics tests the design thought and cultural quality of purple sand artisans, and endless emergence of adornment technique also

${ }^{6}$ Zhang Pu Sheng, Wang Jianhua. Identification and Appreciation of Yixing Purple Sand [M ]. Jiangxi Fine A rts Publishing House, 2000. 
expanded the road of purple sand. Purple sand art originates from life, and the fastidiousness of decoration also comes from life. The visual experience that different adornment skill place brings a person is distinct, and there is no such thing as good or bad decoration. Proper adornment adds color to purple clay implement, excessive adornment appears too vulgar, making it lose its proper artistic language.

\section{Selection of beauty index of purple clay pot}

As for the question of how to quantify the "beauty" in the design aesthetics of purple clay pot, we carry out aesthetic analysis of "plain ware" of purple clay pot from the perspective of vision with "SD" Quantization Form 1, judge the visual aesthetic feeling of the optical purple clay pot from the angle of shape proportion, to provide a reference for the purple sand artisan and "plain ware" purple sand pot market.

Generally speaking, the ratio of objects is the ratio of the length to the width of an object, which is mathematically just a formula for two ratios being equal. We tend to pay more attention to the golden ratio in life, "Mona Lisa" painted by L eonardo Da Vinci @ is the greatest achievement of the golden ratio. We also often use other aesthetic proportions: 1/1, 1/1.414, 1/1.732 and 1/2. In artistic creation, we usually focus on composition and proportion, so do we in product design. We calculate the shape proportion of the product by the common aesthetic proportion. By calculating the approximate degree between the ratio of length and width of the utensils and the aesthetic ratio in common use, the proportion degree of $D_{p j}$, is obtained:

$$
D_{p j}=P_{\text {object }}
$$

$P_{\text {object }}=t_{j}, \min \left(\left|t_{j}-t\right|, j=s q, r 2, g r, r 3, d s\right)$

$$
\mathrm{t}=\left\{\begin{array}{l}
r, r \leq 1 \\
\frac{1}{r}, r \geq 1
\end{array}, \quad r=\frac{H}{B}\right.
$$

Note: $H$ and $B$ are the height and width of the object respectively, and $t_{j}$ is the ratio of shape $j$.

$$
\left\{t_{s q}, t_{r 2}, t_{g r}, t_{r 3}, t_{d s}\right\}=\{1 / 1,1 / 1.414,1 / 1.618,1 / 1.732,1 / 2\}
$$

As shown in the table below, I selected 20 pots from the plain clay pot as the experimental samples, among which sample 1, sample 5, sample 12, sample 16, sample 18, sample 20 belong to the spherical pot, which can be subdivided. Sample 1, sample 5, sample 18, sample 20 are round abdomen with the largest diameter in the middle; In sample twelve, the ampulla is convergent above and plump below, and the body of the pot is piriform; In sample 16, the degree of upper fullness and lower convergence of ampulla is not obvious; Sample 4 is hemispherical pot, wide mouth, smooth shoulders, full abdomen, wide flat bottom; Sample 3, sample 7, sample 8, sample 17 and sample 19 all belong to oblate pot; Sample 3, sample 8, sample 17 and sample 19 are folded abdomen, the abdomen converges from the fold to the spout and bottom of the pot, and the upper and lower contours are basically symmetrical; The spout of sample 7 is straight, with sliding shoulder, bulging ampulla, and relatively flat body; Sample 9 is a trapezoidal round pot, sliding shoulder, round belly shaped pot body like a bell, and the body is higher; Sample 2, sample 14 and sample 15 are all square vessels, among which sample 14 is a four-square pot with a trapezoidal structure with a narrow top and a wide bottom; Both sample 2 and sample 15 belong to hexagonal pot, among which sample 2 has a round straight spout, folded shoulder and round lid; Sample 15 has a six-sided spout with a square lid and a curved top and bottom; Sample six is a mitral pot, the abdomen is square in the circle, the neck of the pot is closed, and the lid, neck and foot of the pot are all six square with a pearl shaped button; Sample 13 is a tile pot, and sample 11 is a pot in the style of a straw hat, and neither type is fractional.

Table 5: Sample Scale (drawn by the author)

\begin{tabular}{|c|c|c|c|c|}
\hline Sample N 0. & Sample 1 & Sample 2 & Sample 3 & Sample 4 \\
\hline Type of ware & &
\end{tabular}




\begin{tabular}{|c|c|c|c|c|}
\hline $\begin{array}{l}\text { Wide* high } \\
\quad(\mathrm{mm})\end{array}$ & $150 * 113$ & $146 * 110$ & $148 * 62$ & $105 * 112$ \\
\hline Ratio (divisor) & 0.7533 & 0.7534 & 0.4189 & 1.0667 \\
\hline $\begin{array}{c}\text { A pproximate } \\
\text { proportionality }\end{array}$ & 0.7072 & 0.7072 & 0.5 & 1 \\
\hline Sample No. & Sample 5 & Sample 6 & Sample 7 & Sample 8 \\
\hline \multicolumn{5}{|l|}{ Type of ware } \\
\hline $\begin{array}{l}\text { Wide* high } \\
\quad(\mathrm{mm})\end{array}$ & $163 * 116$ & $110 * 93$ & $173 * 86$ & $170 * 74$ \\
\hline Ratio (divisor) & 0.7117 & 0.8455 & 0.4971 & 0.4353 \\
\hline $\begin{array}{l}\text { A pproximate } \\
\text { proportionality }\end{array}$ & 0.7072 & 1 & 0.5 & 0.5 \\
\hline Sample No. & Sample 9 & Sample 10 & Sample 11 & Sample 12 \\
\hline \multicolumn{5}{|l|}{ Type of ware } \\
\hline $\begin{array}{l}\text { Wide* high } \\
\quad(\mathrm{mm})\end{array}$ & $143 * 118$ & $165 * 105$ & $122 * 78$ & $120 * 183$ \\
\hline Ratio (divisor) & 0.8252 & 0.6364 & 0.6393 & 1.525 \\
\hline $\begin{array}{l}\text { A pproximate } \\
\text { proportionality }\end{array}$ & 1 & 0.618 & 0.618 & 1 \\
\hline Sample No. & Sample 13 & Sample 14 & Sample 15 & Sample 16 \\
\hline \multicolumn{5}{|l|}{ Type of ware } \\
\hline $\begin{array}{l}\text { Wide* high } \\
\quad(\mathrm{mm})\end{array}$ & $131 * 74$ & $144 * 97$ & $185 * 137$ & $185 * 145$ \\
\hline Ratio (divisor) & 0.5649 & 0.6736 & 0.7405 & 0.7838 \\
\hline $\begin{array}{l}\text { A pproximate } \\
\text { proportionality }\end{array}$ & 0.577 & 0.7072 & 0.7072 & 0.7072 \\
\hline Sample No. & Sample 17 & Sample 18 & Sample 19 & Sample 20 \\
\hline
\end{tabular}




\begin{tabular}{|c|c|c|c|c|}
\hline Type of ware & & & & \\
\hline $\begin{array}{c}\text { Wide* high } \\
\text { (mm) }\end{array}$ & $135^{*} 145$ & $135 * 90$ & $115 * 60$ & $150 * 104$ \\
\hline Ratio (divisor) & 1.0741 & 0.6667 & 0.5217 & 0.6933 \\
\hline $\begin{array}{c}\text { Approximate } \\
\text { proportionality }\end{array}$ & 1 & 0.7072 & 0.5 & 0.7072 \\
\hline
\end{tabular}

The SD survey method, namely the semantic difference method, was first proposed in 1957. It was originally applied to the psychological measurement, and was also known as the "feeling recording method", which is a method of quantitative analysis of the investigated objects through the "SD" questionnaire survey. In order to dig out the perceptual images of most people, it is necessary to conduct statistical analysis on the data obtained from the survey, and calculate the mean and standard deviation of product image evaluation according to formula (4) and formula (5).

$$
\bar{A}_{i}=\longdiv { \sum _ { i = 1 } ^ { K } A _ { i } / K }
$$

$$
\bar{\sigma}=\sqrt{\sum_{i=1}^{k}\left(\overline{A_{i}}-A_{i}^{k}\right)^{2} /(K-1)}
$$

Note: where, $\bar{A}_{i}$ and $\bar{\sigma}$ respectively represent the mean and standard deviation of the aesthetic value and image evaluation value of the $\mathrm{No}$. purple clay pot sample.

In accordance with the evaluation value, and according to the pauta criterion, the survey data of residual error $\overline{G_{i}}=\left|A_{i}-\overline{A_{i}}\right| \geq 3 \sqrt{\sigma}$ are removed, and the average value obtained is the reasonable aesthetic evaluation value.

This time, 20 plain pot model samples were selected to make a 5-order SD questionnaire, as shown in the figure, and 109 valid questionnaires were obtained. In the process of investigation, each subject should give an intuitive evaluation on the aesthetic feeling of purple clay pot: "1" means not beautiful, "2" means general beautiful, "3" means beautiful, "4" means relatively beautiful, and "5" means very beautiful.

Table 6: "SD" M easurement Table (made by the author)

\begin{tabular}{|c|c|c|c|c|c|c|c|}
\hline $\begin{array}{c}\text { Sample } \\
\text { N 0. }\end{array}$ & $\begin{array}{c}\text { A esthetic } \\
\text { Feeling }\end{array}$ & $\begin{array}{c}\text { Sample } \\
\text { N o. }\end{array}$ & $\begin{array}{c}\text { A esthetic } \\
\text { Feeling }\end{array}$ & $\begin{array}{c}\text { Sample } \\
\text { No. }\end{array}$ & $\begin{array}{c}\text { A esthetic } \\
\text { Feeling }\end{array}$ & $\begin{array}{c}\text { Sample } \\
\text { No. }\end{array}$ & $\begin{array}{c}\text { A esthetic } \\
\text { Feeling }\end{array}$ \\
\hline Sample 1 & 3.06 & Sample 2 & 3.24 & Sample 3 & 3.24 & Sample 4 & 3.14 \\
\hline Sample 5 & 3.18 & Sample 6 & 2.94 & Sample 7 & 3.06 & Sample 8 & 3.30 \\
\hline Sample 9 & 3.19 & $\begin{array}{c}\text { Sample } \\
10\end{array}$ & 3.17 & Sample 11 & 2.83 & Sample 12 & 3.12 \\
\hline $\begin{array}{c}\text { Sample } \\
13\end{array}$ & 3.05 & $\begin{array}{c}\text { Sample } \\
14\end{array}$ & 3.11 & $\begin{array}{c}\text { Sample } \\
15\end{array}$ & 3.20 & Sample 16 & 3.27 \\
\hline $\begin{array}{c}\text { Sample } \\
17\end{array}$ & 3.01 & $\begin{array}{c}\text { Sample } \\
18\end{array}$ & 3.27 & $\begin{array}{c}\text { Sample } \\
19\end{array}$ & 3.18 & Sample 20 & 3.22 \\
\hline
\end{tabular}

According to the degree of aesthetic feeling and the degree of similar proportion, it is found that the samples with similar proportion degree close to 0.5 have higher aesthetic feeling, while those with similar proportion degree close to 0.618 have the lowest aesthetic feeling in this survey. From this questionnaire, it can be known that the purple clay pot with a proportion close to 0.5 will be more in line with the visual beauty of people.

\section{Epilogue}

To establish an aesthetic evaluation system for purple clay pot, first of all, we must understand the needs of modern people for purple clay pot. The production of purple clay pot is to meet peoplec demand for tea. As people change from "guzzling" to "drinking" to "tea-tasting", the proportion of purple clay pot changes with the change of tea culture. Through field trips and tea culture experiences, people now mostly use the opposite sitting mode when drinking tea, that is, "one person 
makes the tea, several people sit opposite to taste". This tea tasting mode reduces the output of large capacity and large shape purple clay pots such as loop-handled teapots and mitral pots. On the contrary, the purple clay pot with a small size is more popular because it has a smaller proportion and a smaller volume, which makes it easier to control water flow and more comfortable to hold.

In this paper, the "SD" method is used to quantify the visual and perceptual beauty of purple clay pot, and its proportion is used as the reference data for the change of beauty. From the qualitative and quantitative aspects of the purple clay pot of the plain ware, this paper analyzes the proportional aesthetic degree of the purple clay pot and makes people@ perceptual understanding of the purple clay pot clearer and more specific in the form of data quantification and mathematical calculation. Such an evaluation method is more scientific and objective than people@ perceptual cognition. We can make use of the data to assist the design of purple clay pot, and help designers develop works that more correspond to the visual beauty of consumers, to improve the market competitiveness of the product.

\section{Acknowledgements:}

The authors acknowledge support Propagation of A ncient Chinese Catering Utensils Cultures under the Technology and Form Perspective base by General Art Projects of National Social Science Fund of China (N 0.17B G 123).

\section{References}

1. Yang Yong Shan. (1988). Ceramic Modeling Design [M]. Liaoning Science and Technology Press. Shenyang.

2. Zhou Gao qi. Yang Xian Teapot Series. Ming Dynasty.

3. Zhou Guo Xin. (2019).A Brief Analysis of the A rtistic Charm of "Xi Shi Pot". [J]. Shandong Ceramics. 47-47.

4. Jiang Xia.(2011). Preliminary Study on Properties and Technology of Yixing Purple Sand in Successive Dynasties. [J]. Jingdezhen Ceramic Institute.1-67.

5. Li Li Xin. (2012).Imitation Theory of Reconstruction of Creation -- the Origin of the Shape of Purple Sand Ware. [J]. Creativity and Design. 71-76.

6. Liu Ting, Zhang Fu Chang. (2012).The Pot Body Design of Y ixing Traditional Purple Clay Teapot. [J]. B eauty and Times.9-16.

7. Wu Juan, Zhang $M$ ao Lin, Wu Jun Ming, Li Qi Jiang, Yu Yong Bin, Liang Duo and Fang Tao.
(2011).Study on Properties of Yixing Purple Clay. [J]. J iangsu Ceramics. 20-23+25.

8. Li Zhou. (2018).Research on the Formation Technology of Yixing Purple Clay Flower A pparatus. [J]. Nanjing U niversity. 1-66.

9. Yang Fei Yi.(2017). Study on the Shape and Decoration of Y ixing Purple Sand Plain Pot in M ing and Qing Dynasties. [J]. N anjing university. 1-75.

10. Han Rong. (2011).Study on Tin Drinking Utensil in Qing Dynasty. [J]. Packaging Engineering. 105-108.

11. Han Rong. (2015). Research on Color-adding Purple Sand Drinking Utensil in Qing Dynasty. [J]. China Ceramics.67-70.

12. Zhang Pu Sheng, Wang Jianhua. (2000).Identification and Appreciation of Yixing Purple Sand $[\mathrm{M}]$. Jiangxi Fine Arts Publishing House.N anchang. 